\title{
Molecular cloning and expression of a new gene, GON-SJTU1 in the rat testis
}

\author{
Zhao-juan Yang ${ }^{+1}$, Ning Sun ${ }^{+1}$, Shu-qin Wang ${ }^{1}$, Geng G Tian² and Ji Wu*1
}

\begin{abstract}
Background: Spermatogenesis is a complex process involving cell development, differentiation and apoptosis. This process is governed by a series of genes whose expressions are highly regulated. Male infertility can be attributed to multiple genetic defects or alterations that are related to spermatogenesis. The discovery, cloning and further functional study of genes related to spermatogenesis is of great importance to the elucidation of the molecular mechanism of spermatogenesis. It is also physiologically and pathologically significant to the therapy of male infertility.

Methods: GON-SJTU1 was identified and cloned from rat testis by cDNA library screening and 3'-and 5'-RACE. The products of GON-SJTU1 were assessed by Northern and Western blotting. The expression of GON-SJTU1 was also examined by In situ hybridization and immunohistochemistry.

Results: Here we identified and cloned a new gene, GON-SJTU1, with the biological process of spermatogenesis. GONSJTU1 is highly expressed in the testis from day 1 to 15 and then decreased, suggesting that GON-SJTU1 might be a time-related gene and involved in the early stage of spermatogenesis. And the expression of GON-SJTU1 in the testis occurred in some male germ cells, particularly in gonocytes and spermatogonial stem cells.
\end{abstract}

Conclusion: GON-SJTU1 may play a role in the biological process of spermatogenesis.

\section{Background}

With the increase of infertility rates in couples, the cellular and molecular mechanisms involved in spermatogenesis have held the interest of many biologists and researchers. This complex process involves cell development, differentiation and apoptosis. Spermatogenesis is initiated by the conversion of gonocytes to spermatogonial stem cells [1-4]. The spermatogonia form the resident stem cell. It constantly divides by mitosis and differentiates through meiosis and spermiogenesis to form spermatocytes, spermatids and spermatozoa [5].

The coordinated maturation of spermatogonia, spermatocytes, and spermatids need a precise and concordant regulatory system, which comprises a large group of regulators, signals, and other factors. We recently demonstrated the importance of short-type PB-cadherin (STPB-C) in gonocyte survival, proliferation and selfrenewal of spermatogonial stem cells (SSCs) [6-8]. More-

\footnotetext{
* Correspondence: jiwu@sjtu.edu.cn

1 School of Life Sciences and Biotechnology, Shanghai Jiao Tong University,

Shanghai, 200240, China

+ Contributed equally

Full list of author information is available at the end of the article
}

over, we found that STPB-C promoted self-renewal of SSCs via activating Janus kinase/signal transducer and activator of transcription (JAK-STAT) and phosphoinositide-3 kinase (PI3-K)/Akt, and blocking transforming growth factor (TGF)- $\beta 1$ signaling [8]. Glial cell linederived neurotrophic factor (GDNF), produced by Sertoli cells, has been reported essential for spermatogonial stem cell maintenance [9].

Stem cell factor (SCF) and its receptor c-kit consisting of a key signaling system, which appears to regulate the proliferation of spermatogonia [10]. Prabhu et al. demonstrated that the expression of c-kit was indeed concordant with spermatogonial differentiation [11]. Bcl-2 family members are key regulators of apoptosis. Some can promote cell survival while others support cell death $[12,13]$. Currently, Yan et al. have reported the involvement of Bcl-2 family proteins in germ cell apoptosis during rat testicular development [14]. The regulation of the $\mathrm{SCF} / \mathrm{c}$-kit system in the proliferation and survival of spermatogonia appears to be through controlling the expression of some Bcl-2 family of proteins $[10,14,15]$.

At present, some research groups have demonstrated stage-specific expression patterns of many genes in 
rodents by microarray analysis, indicating that stage-regulated expression of genes is a widespread and fundamental event during spermatogenesis $[16,17]$. Johnson et al. reported that cadherins, with the exception of N-cadherin and cadherin- 6 , were expressed most abundantly around postnatal day 7 [18]. In addition, for all members of the PCDH $\alpha$ family of cadherins, expression levels were generally high at day 7 and then remained at a steady state from postnatal day 21 through adulthood [18]. This pattern is in contrast to that of STPB-C, which is expressed at high levels between days 1 and 5 , with a subsequent large drop by day 10 [6], suggesting a distinct role of STPB-C in spermatogenesis. These reports have contributed valuable information for further studies into the identification of spermatogenesis-related genes.

In the present study, we identified and cloned a new gene, GON-SJTU1. Its mRNA contains an open reading frame of $771 \mathrm{bp}$ and is predicted to encode a protein of 256 amino acids. We studied its expression in germ cells of rat testis at different days after birth, and speculate that GON-SJTU1 play a role in the early steps of spermatogenesis.

\section{Methods}

Animals

About 180 pups from different litters were obtained by mating Sprague-Dawley rats (Charles River Breeding Labs, Kingston, RI, USA). All protocols involving animals were approved by the Institutional Animal Care and Use Committee of Shanghai, in accordance with the National Research Council Guide for Care and Use of Laboratory Animals.

\section{Preparation of probes}

Drosophila unpaired genes were previously assigned key functions in the regulation of the JAK signaling pathway and self-renewal of spermatogonial stem cells [19-21]. To clone the homolog of the unpaired gene in rats, we focused on the conserved protein sequence of Drosophila unpaired genes, and then translated the protein sequence back to a nucleotide sequence that was possibly encoded in rat. To produce screening probes, the PCR primers (forward primer: 5'-CAGGGGAATCCGACTGTTTA-3'; reverse primer: 5'-TCCGTAGGTAGGGACAGTGG-3') were designed with this purpose.

Total RNA was obtained from rat testis with TriZol reagent (Invitrogen, Carlsbad, CA, USA) as recommended. Using oligo $(\mathrm{dT})_{12-18}$ primer (Life Technologies, Gaithersburg, MD), cDNA was synthesized by reverse transcription of $2 \mu \mathrm{g}$ total RNA with Superscript II RNase $\mathrm{H}^{-}$reverse transcriptase according to the manufacturer's instructions (Life Technologies). One-tenth of the reverse transcription reaction was used for PCR amplification on a thermal cycle (PTC-100 Peltier Thermal Cycler, BioRad, Hercules, CA, USA) with primers (see above). The amplified DNA probe was separated by gel electrophoresis and purified using a Gel Extraction Mini Kit (Qiagen, Valencia, CA, USA).

\section{cDNA library screening}

For the screening process, $50 \mathrm{ng}$ of DNA probe obtained above was randomly labeled with $[\gamma-32 \mathrm{P}]$ ATP using Prime a Gene labeling system (Promega, Madison, WI, USA). The hybridization probe was used to screen approximately 106 plaques of a rat testis cDNA library. The Lambda ZAP II Library was purchased from Stratagene. The plating of the library and subsequent plaque lift were conducted using standard procedures (Stratagene, La Jolla, CA). The plaques exhibiting positive signals were excised as pBluescript SK(-) phagemids. Ten positive clones were isolated and sequenced using the T3 and T7 promoter primers.

To clone the full-length cDNA sequence of the new gene, $3^{\prime}$-and $5^{\prime}$ - RACE reaction (5' primer: 5'-GGGTCTTCCGTACGCCACAT-3'; 3' primer: 5'-GTGCTCGTGATTAATCACAGG-3') were performed using a SMART RACE cDNA amplification kit (Clontech, Palo Alto, CA, USA) with total RNA extracted from rat testis, according to the manufacturer's instructions.

\section{Construct}

A 782 bp fragment containing the ORF of GON-SJTU1 (771bp) was generated by PCR with the primers (forward primer: 5'-TTGTCGACAATGCAGCCCAAAGCG-3'; reverse primer: 5'-CGCTCGAGTTATGTATATGAGTACAC-3') and digestion with restriction enzymes (SalI, XhoI). The fragment was then subcloned into SalI-XhoI sites of the pCMV-Myc Mammalian Expression Vector (Clontech), creating an in-frame fusion to the Myc tag (pCMV-Myc-GON-SJTU1) for transfection [22,23].

\section{Northern blot analysis}

Total RNA isolated from various rat tissues (brain, heart, liver, lung, kidney, adrenal, ovary, and testis) and testes on days $1,3,5,10,15,20$ and 60 was obtained as described above. Northern analysis was performed as described in Wu et al. [6]. In brief, samples (10 $\mu \mathrm{g}$ RNA/lane) were run on a $1 \%$ agarose-formaldehyde gel. The samples were then transferred by capillary action to a nylon membrane (Amersham Pharmacia Biotech, Arlington Heights, IL, USA) in $20 \times$ SSC overnight. After prehybridizing for 30 min in Rapid-Hyb (Amersham Pharmacia Biotech), blots were hybridized with a ${ }^{32} \mathrm{P}$-labeled cDNA probe (a $782 \mathrm{bp}$ fragment containing the ORF of GON-SJTU1, see above) produced with the Rediprime kit (Amersham Pharmacia Biotech) following the manufacturer's instructions. Blots 
were then washed in decreasing concentrations of SSC, $0.1 \%$ SDS. Autoradiography was performed with Kodak BioMax film (Eastman Kodak, Rochester, NY, USA). Using the StripEz DNA kit (Ambion, Austin, TX, USA), the blots were stripped and then re-probed for G3PDH with a probe produced from a commercially available rat template (Ambion).

\section{In situ hybridization}

Using T3 and T7 RNA polymerase for sense and antisense probes respectively, DIG-labeled cRNAs of GONSJTU1 were produced with DIG RNA labeling kit (Roche Molecular Biochemicals, Mannheim, Germany) from linearized pBluescript SK(-) vector with a GON-SJTU1 insert. Paraffin-embedded tissues of the testis on days 1, 5 and 60, were prepared. The analysis of in situ hybridization was performed as mentioned previously [6].

\section{Western immunoblotting}

Lysates of rat testes on days 5, 10, 15, 20 and 60 were obtained as described previously [22]. Immunoblotting was performed using an affinity-purified polyclonal antibody raised in rabbits against the specific peptide sequence (LVEEKMKNHEGNGTD) to GON-SJTU1 by a commercial source (Invitrogen, Carlsbad, CA, USA). The identification of specificity of this polyclonal antibody was applied according the method described by Yang and $\mathrm{Wu}[8]$.

\section{Immunohistochemistry}

Testis of rat on day 7 was prepared and embedded in paraffin according the method described by Yang and $\mathrm{Wu}$ [8]. The testis sections were dewaxed and immunofluorescence-stained specific to GON-SJTU1. The antiGON-SJTU1 polyclonal antibody used was same as that used in the Western immunoblotting experiments. The experimental details of the immunohistochemical process were described elsewhere [22,24].

\section{Data analysis}

The nucleotide sequence was deduced and analyzed at the NCBI website [25]. The deduced nucleotide sequence reported in this paper has been submitted to the GenBank with accession number EU605813. The protein sequence was also analyzed by NetPhos and NetPhosK Server [26,27].

For each Northern analysis, densitometry was used to obtain a numerical value for the GON-SJTU1 signal and $G 3 P D H$ signal, and the final data for each sample were expressed as a ratio of these values. Each analysis was performed in triplicate, and the mean values obtained from these three experiments for each treatment group were then analyzed statistically with one-way ANOVA (analysis of variance) and a student-Newman-Keuls test.

\section{Results}

\section{Cloning of rat GON-SJTU1 gene}

Using the probes (see Methods), library screening of the rat testis cDNA library resulted in identification of positive clones. The coding sequence was completed by 3 'and $5^{\prime}$-RACE reaction. The sequence analysis revealed a 1717 bp nucleotide sequence with an open reading frame of $771 \mathrm{bp}$ predicting a 256 -amino-acid protein (Figure 1). Protein of approximately $25 \mathrm{kDa}$ was detected by Western blot analysis. The results of Western blot analysis using anti-GON-SJTU1 antibody and that with an antimyc antibody were consistent with data obtained using the protein from $293 \mathrm{~T}$ cells transfected by pCMV-MycGON-SJTU1 vector, indicating that the anti-GON-SJTU1 antibody specifically recognized the GON-SJTU1 protein (Figure $2 \mathrm{~A}$ ). In rat testis, the GON-SJTU1 protein was also shown to be approximately $25 \mathrm{kDa}$ (Figure $2 \mathrm{~B}$ ).

A database BLAST search indicated that no homologues had previously been identified or studied and no conserved domain had been reported either. This rat gene was a new type, which was named GON-SJTU1. Several predicted phosphorylation sites mainly focused within the two terminal portions of the GON-SJTU1 protein, particularly the $\mathrm{N}$ terminal (Figure 3 ). The predicted sites for casein kinases 1, 2 (CK1, CK2), PKC and PKA were collected in $\mathrm{N}$ - and $\mathrm{C}$-terminal portions of the proteins. Only one Src site was identified in the middle portion of the protein.

\section{Expression of GON-SJTU1 mRNA in all rat adult tissues tested}

The rat GON-SJTU1 cDNA probe recognized a single RNA transcript of $\sim 5 \mathrm{~kb}$ (Figure 4). By Northern blot analysis, GON-SJTU1 mRNA was detected not only in rat testes on day $60(\mathrm{n}=4)$, but also in all of the other tissues tested (Figure 4).

\section{Diverse expression of GON-SJTU1 in rat testes on different days}

To focus on the role of the GON-SJTU1 protein in rat testes, Northern blot analysis was performed. As shown in Figure 5, GON-SJTU1 expression was exhibited in an agedependent manner in postnatal rat testis. A strong signal of its mRNA was found in the early juvenile rat (on day $1 \sim 15)$; however, there was a sharp decrease in its expression level when testes were obtained from 20 - and 60day-old rats (Figure 5).

The results of Western blotting with anti-GON-SJTU1 antibody were consistent with the results of Northern blot analysis (Figure 6). 
ctggtgcgga ccaggggaat ccgactgttt aattaaaaca aagcatcgcg aaggccegcg gcgggtgttg acgcgatgtg atttctgccc agtgctctga atgtcaaagt gaagaaattc aatgaagcgc gggtaaacgg cgggagtaac tatgactctc ttaaggtagc caatgcctc gtcatctaat tagtgacgcg catgaatgga tgaacgagat tcccactgtc cctacctact tccctcagta acggcgagtg aacagggaag agcccagcgc cgaatccccg ccgcgcgccg cggcgeggga aatgtggegt acggaagacc cactcccegg cgccgctcgt ggggggccca agtccttctg atcgaggccc agcccgtgga cggtgtgagg ccggtagcgg cccccggcgc gccgggcccg ggtcttcccg gagtcgggtt gettggga atg cag ccc aaa gcg ggt ggt aaa ctc

1 cat cta agg cta aat acc ggc acg aga cga agc aaa act act gta agt gga gga gag gaa $\begin{array}{lllllllllllllllllllll}10 & H & L & R & L & N & T & G & T & R & R & S & K & T & T & V & S & G & G & E & E\end{array}$ gag tca gac tta aac atg gca tca ggg gat gag caa agc agg tgt aat agc agc gag agc $\begin{array}{llllllllllllllllllllll}30 & \text { E } & \text { S } & \text { D } & \text { L } & \text { N } & \text { M } & \text { A } & \text { S } & \text { G } & \text { D } & \text { E } & \text { Q } & \text { S } & \text { R } & \text { C } & \text { N } & \text { S } & \text { S } & \text { E } & \text { S }\end{array}$ cat cag tca ttg gtt gaa gaa aaa atg aag aac cat gaa ggc aat gga aca gac aga gct $\begin{array}{lllllllllllllllllllll}50 & H & Q & S & L & V & E & E & K & M & K & N & H & E & G & N & G & T & D & R & A\end{array}$ gaa ttc ccc tat gat gct gct get ggt gct ggt get tct get ggt gct ggt get ggt ggt $\begin{array}{llllllllllllllllllllll}70 & \text { E } & \text { F } & \text { P } & \text { Y } & \text { D } & \text { A } & \text { A } & \text { A } & \text { G } & \text { A } & \text { G } & \text { A } & \text { S } & \text { A } & \text { G } & \text { A } & \text { G } & \text { A } & \text { G } & \text { G }\end{array}$ get get ggt get get gct ggt get tct get ggt get ggt get ggt gct ggt get ggt gct

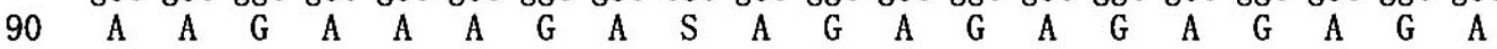
ggt gct ggt get ggt gct ggt get ggt get tct gct ggt gct ggt gct ggt get gac get $\begin{array}{llllllllllllllllllllllll}110 & \text { G } & \text { A } & \text { G } & \text { A } & \text { G } & \text { A } & \text { G } & \text { A } & \text { G } & \text { A } & \text { S } & \text { A } & \text { G } & \text { A } & \text { G } & \text { A } & \text { G } & \text { A } & \text { D } & \text { A }\end{array}$ ggt gct gct ggt gat tgt ggt ggt ggt ggt gcc tct gct gct get gtt ggt ggt gat ggt

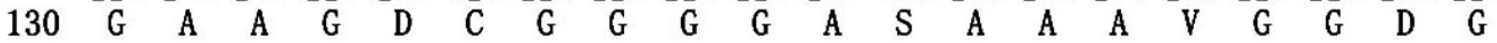
ggt ggt agt aat ggt ggt ggt ggt agt ggt ggt ggt ggt agt agt gct agt ggt act gtt 1065

$\begin{array}{lllllllllllllllllllll}150 & G & G & S & N & G & G & G & G & S & G & G & G & G & S & S & A & S & G & T & V\end{array}$ gtt act gct gct gct gct gct gct gct ggt gat get get agt gct gct gct gct gct act 1125 $\begin{array}{llllllllllllllllllllll}170 & \text { V } & \text { T } & \text { A } & \text { A } & \text { A } & \text { A } & \text { A } & \text { A } & \text { A } & \text { G } & \text { D } & \text { V } & \text { V } & \text { S } & \text { A } & \text { A } & \text { A } & \text { A } & \text { A } & \text { T }\end{array}$ gtt agt get get get gct get act get ggt get gct get gct get get ggt ggt agt get 1185

$\begin{array}{lllllllllllllllllllll}190 & \text { V } & \text { S } & \text { A } & \text { A } & \text { A } & \text { A } & \text { A } & \text { T } & \text { V } & \text { G } & \text { A } & \text { A } & \text { A } & \text { A } & \text { A } & \text { A } & \text { G } & \text { G } & \text { S } & \text { V }\end{array}$ agt gct gct gct get gct get ggt ggt agt gtt agt gct get get gct act gtt gat gct 1145

$\begin{array}{lllllllllllllllllllllllllll}210 & \text { S } & \text { A } & \text { A } & \text { A } & \text { A } & \text { A } & \text { A } & \text { G } & \text { G } & \text { S } & \text { V } & \text { S } & \text { A } & \text { A } & \text { A } & \text { A } & \text { T } & \text { V } & \text { D } & \text { A }\end{array}$ get gct get tct aca agg gat gaa ctg gtt cta cag agt gag ttc cag gat ctg aag aca 1205 $\begin{array}{lllllllllllllllllllll}230 & \text { A } & \text { A } & \text { A } & \text { S } & \text { T } & \text { R } & \text { D } & \text { E } & \text { L } & \text { V } & \text { L } & \text { Q } & \text { S } & \text { E } & \text { F } & \text { Q } & \text { D } & \text { L } & \text { K } & \text { T }\end{array}$ gcg aca gtg tac tca tat aca taa a aatagttttt aaattttatt ttttaaaaa gtagtttaat 1270

$\begin{array}{lllllllll}250 & \mathrm{~A} & \mathrm{~T} & \mathrm{~V} & \mathrm{Y} & \mathrm{S} & \mathrm{Y} & \mathrm{T} & -\end{array}$ agtaaaagaa gttcgaaata taagaacctc acatcagcca ggcagtggtg gtgctcgtga ttaatcacag 1340 gactcgggag gcagacgcaa gtggatattt atgagttcaa gttaagcatg gtctacagag tgagttccag 1410 gggaattccg taggtaggga cagtgggaat ctcgttcatc cattcatgcg cgtcactaat tagatgacga 1480 ggcatttggc taccttaaga gagtcatagt tactcccgcc gtttacccgc gcttcattga atttcttcac 1550 tttgacattc agagcactgg gcagaaatca catcgcgtca acacccgccg cgggccttcg cgatgctttg 1620 ttttaattaa acagtcggat tccctggtc cgcaccagtt ctaagtcggc tgctaggcge cggccgaggc 1690 gaggegccgc gcgggaaacc gcggccc

Figure 1 Nucleotide sequence and predicted protein sequence of rat GON-SJTU1. The CDNA of GON-SJTU1 sequenced was approximately 1717 bp with a 771 bp ORF. The initiating codon (ATG) and the stop codon (TAA) are underlined. The predicted protein product of GON-SJTU1 was a polypeptide of 256 amino acids.

\section{Expression of GON-SJTU1 in rat testis germ cells}

In situ hybridization with the GON-SJTU1 probe was performed to examine testes on days 1, 5 and 60 . Within rat testis, GON-SJTU1 mRNA signal was present in some germ cells, especially in gonocytes and spermatogonial stem cells (Figure 7). Immunohistochemistry analysis demonstrated that GON-SJTU1 was indeed expressed in the cytoplasm of some germ cells in the 7-day testis (Figure 8).

\section{Discussion}

A 1717 bp cDNA of GON-SJTU1 gene was cloned, which comprises a 771 bp ORF predictably encoding a 256amino-acid protein. The Northern and Western blotting experiments confirmed the information mentioned above. GON-SJTU1 may be a new type of identified gene, as it has no homologues in the rat or any other animals. No conserved domain had been found in this protein. Only a few phosphorylation sites were predicted in its $\mathrm{N}$ - 


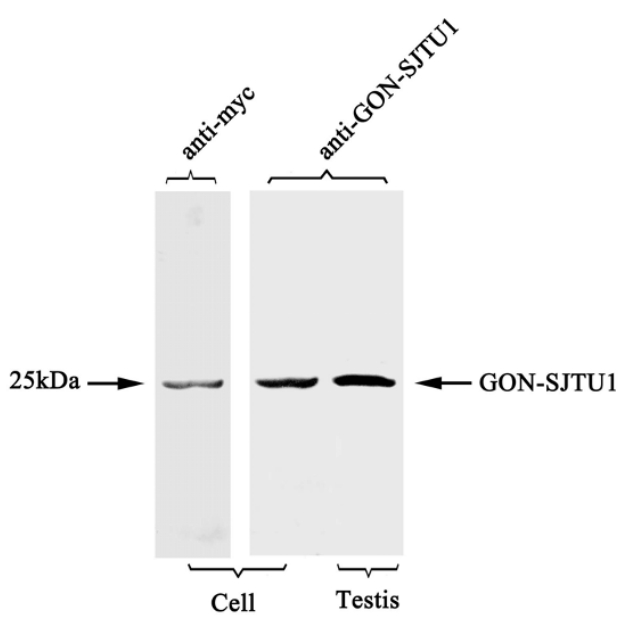

Figure 2 Identification of GON-SJTU1 protein by Western blot analysis. On immunoblots, a single prominent band of about $25 \mathrm{kDa}$ in weight was recognized by anti-GON-SJTU1 antibody both in transfected cells and testis. The result of blotting analysis using anti-myc antibody corresponded with that obtained using anti-GON-SJTU1 antibody.

and $\mathrm{C}$ - terminal portions, most of which are predicted sites for CK2 and PKC. PKC and Src have been found to be involved in germ cell apoptosis of testis $[28,29]$. In addition, Src was shown to be highly expressed at stages VII-VIII [30]. CK2 is also implicated in the regulation of spermatogenesis [31,32]. The question as to whether phosphorylation or dephosphorylation of GON-SJTU1 is associated with its function, and whether PKC, CK2 or Src regulates the function of GON-SJTU1 remains to be answered in future studies.

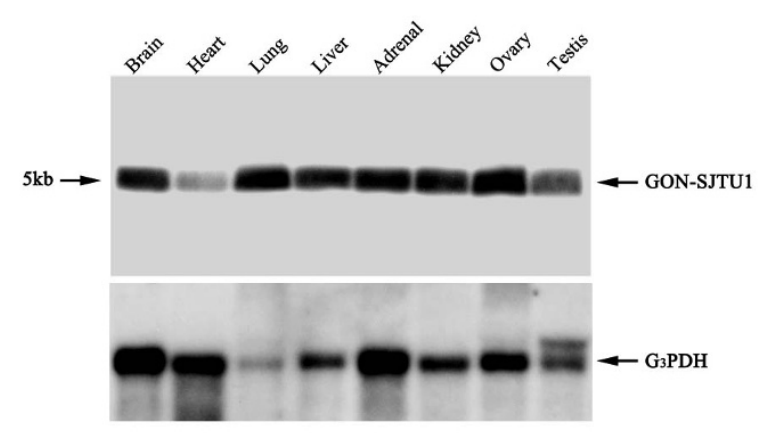

Figure 4 Expression levels of GON-SJTU1 in multiple rat tissues. Northern blot analysis showed that the mRNA of GON-SJTU1 was about $5 \mathrm{~kb}$ in length. The expression of this gene was detected in all tested rat tissues, brain, heart, lung, liver, adrenal, kidney, ovary and testis.

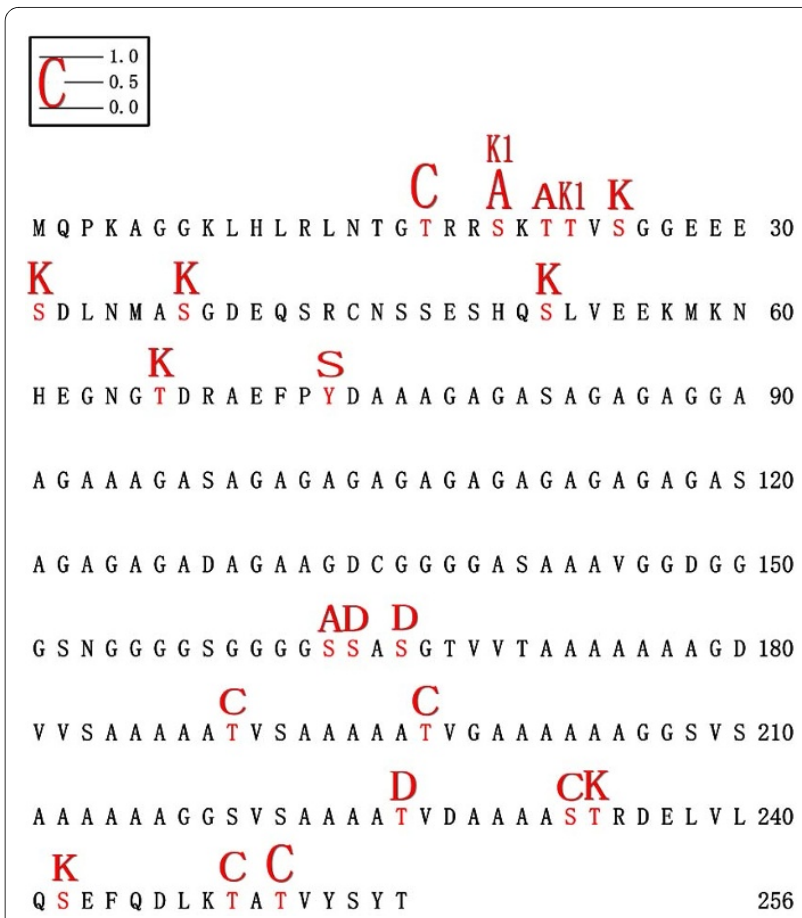

Figure 3 The predicted protein kinesis and the potential position of GON-SJTU1. The predict protein kinesis are represented by different letters with heights equal to the prediction values (0.0-1.0) and plotted along the amino acid sequence position. C: PKC; A: PKA; K: CK2; S: Src; K1: CK1; D: Cdc2.

In this study, we also analyzed the potential role of GON-SJTU1 in rat testis. The results showed that GONSJTU1 had an age-dependent expression profile, and in situ hybridization analysis indicated that mRNA of GONSJTU1 was expressed in some germ cells, including type A spermatogonial stem cells (Figure 7). This implied that GON-SJTU1 may play a role in spermatogenesis. The results of in situ hybridization analysis appeared to coincide with that of Northern and Western blotting using testes of 1- to 60-day-old rat: GON-SJTU1 products were highly expressed in one-day old rat testis, as only the germ cells present are gonocytes at this time. The high expression of GON-SJTU1 protein was constant until day 20 , and showed a sharp decrease from day 15 to day 20, at which the area density and numerical density of germ cells increased to its peak [33].

Furthermore, postnatal development of rat testis has been well characterized by some researchers [5,33-38]. In one-day old animals, gonocytes are the only germ cells present; at 5 days, a mixture of gonocytes and spermatogonial stem cells are found; at day 9, type B germ cells are observed; at day 10 , early spermatocytes at the preleptotene stage are apparent; at day 18-20, meiotic divisions of spermatocytes occur; at day 25 , round spermatids can be observed. The gonocytes resume proliferation to give rise to type A spermatogonial stem cells 
A

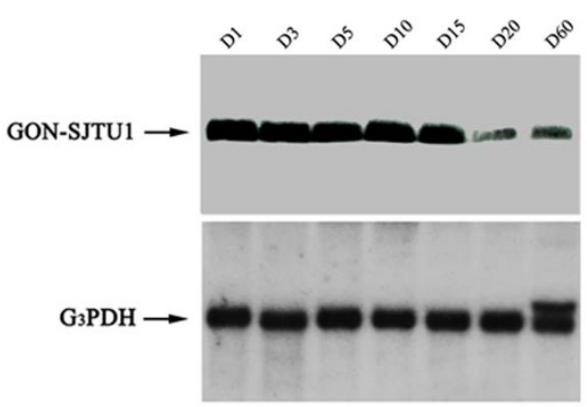

B

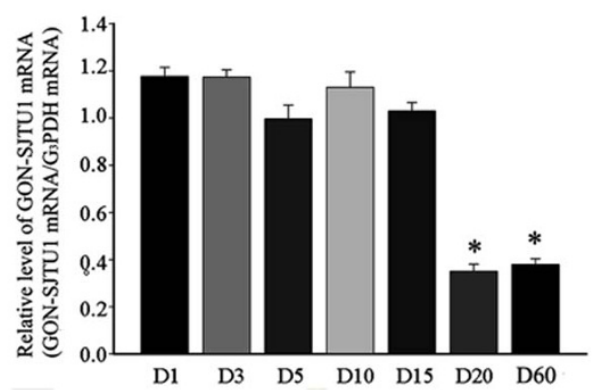

Figure 5 mRNA of GON-SJTU1 was expressed diversely in rat testes at different ages. (A) Representative Northern analysis of GONSJTU1 in total RNA from samples obtained from testes on postnatal days $1,3,5,10,15,20$, or 60 . Expression of G3PDH was used as an internal standard to control for evenness of loading. (B) In each of three replicate analyses, Northern blots were quantified, and the results were expressed as the ratio of GON-SJTU1:G3PDH. The bars represent the means \pm SEM of the data for each age, and bars marked with star were significantly different from each other $(p<0.05)$.

shortly after birth, which marks the start of spermatogenesis. Spermatogonia are converted to primary spermatocytes but the rate increases rapidly only after day 20 $[5,33,35]$.

Base on these data, we determined that the period of high expression of the GON-SJTU1 protein in rat testis correlated with that of early stages of rat spermatogenesis, from the transition of gonocytes to spermatogonia, to the first meiotic division of spermatocytes. This suggested that this protein played a role in these stages of spermatogenesis. However, the details of how GONSTTU1 is involved in the rat spermatogenic process remain unknown.

The results of our study have identified the key timepoint and cell types of GON-SJTU1 expression. The timing of the changes of GON-SJTU1 expression (from day 15 to day 20) is in accordance with the reduction of the rate of spermatogenic progression in rat testis, appearance of meiotic divisions of spermatocytes and the wave of germ cell apoptosis $[14,15,35]$. Therefore, there are at
A

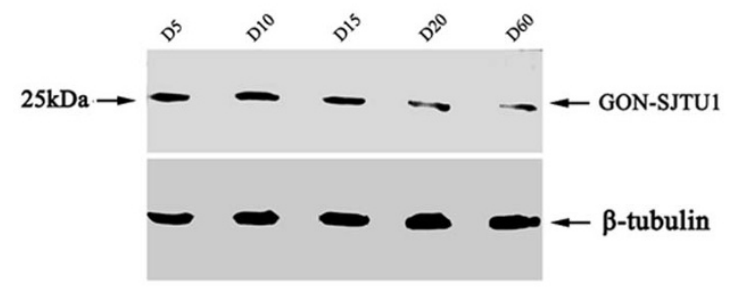

B

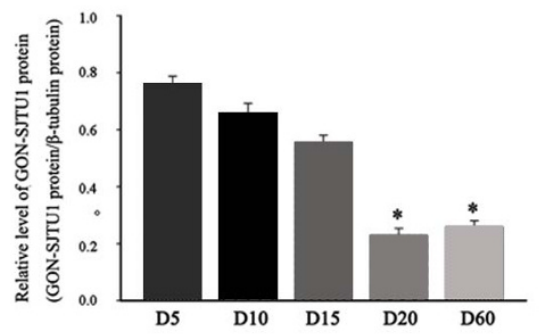

Figure 6 The expression of GON-SJTU1 protein in rat testes at different ages. (A) Representative western analyses of protein from samples obtained from testes on postnatal days $5,10,15,20$, or 60 . The expression of $\beta$-tubulin was used as an internal standard for normalization. (B) In each of three replicate analyses, Western blots were quantified, and the results were expressed as the ratio of GON-SJTU1: $\beta$ tubulin. The bars represent the means \pm SEM of the data for each age, and bars marked with star were significantly different from each other $(p<0.05)$

least three speculations as to how GON-SJTU1 participates in rat spermatogenesis.

First, GON-SJTU1 may be involved in regulating the rate of spermatogenic progression. van Haaster and de Rooij [35] indicated that the rate of progression of spermatogenesis was much higher before day 15 and then strongly reduced. Second, GON-SJTU1 may be involved in cell mitosis. This may also explain why GON-SJTU1 was not only expressed in the testis but also in brain, heart, liver, lung, kidney, adrenal and ovary. Third, GONSJTU1 could relate to the survival of germ cells. The major germ cell type in apoptosis is the spermatocyte on day 20 [14]. However, the expression lever of GONSJTU1 sharply reduced from day 15 to day 20 .

GON-SJTU1 may also participate in some signal networks to regulate spermatogenesis. The expression of the $c$-kit gene has been reported in rat gonocyte from the day of birth to day 5 . This protein has been indicated to be essential for the migration of gonocytes, which is crucial for their survival $[39,40]$. In rats, both mRNA and protein levels of c-kit are highly detected in differentiating spermatogonia, types A1 to A4, and are persistent in low levels in meiotic pachytene spermatocytes [41-43]. Some 

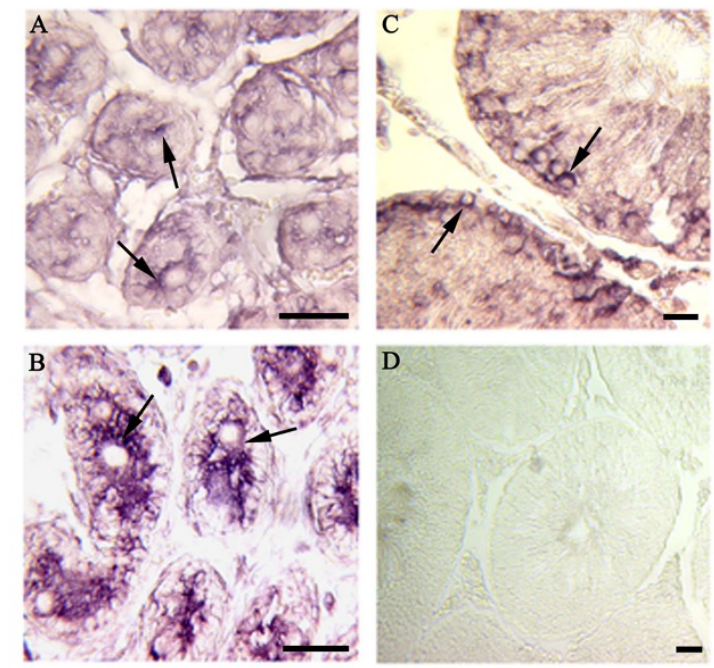

Figure 7 In situ hybridization of GON-SJTU1 mRNA in rat testis

The slides of testis on day 1 (A), day 5 (B), day 60 (C) were analyzed using the DIG-labeled CRNAs probes specific for GON-SJTU1. The signals were observed in some germ cells (pointed with arrows). The negative control was also performed (D). Bar $=50 \mu \mathrm{m}$.

Bcl-2 family members also present an age-development expression pattern. Both Bax and Bcl-w expression levels peak on day 20 and decrease thereafter [14]. It remains to be tested whether GON-SJTU1 takes part in the SCF/ckit signaling system and regulates the function of Bax or Bcl-w. Our studies show that GON-SJTU1 might play a role in spermatogenesis, but the exact details of this role require further study, such as GON-SJTU1 knockout mice are generated and analyzed.

\section{Conclusion}

GON-SJTU1 can express in some male germ cells and may play a role in the biological process of spermatogenesis. The exact mechanism with GON-SJTU1 in the spermatogenesis needs to be clarified in further study.
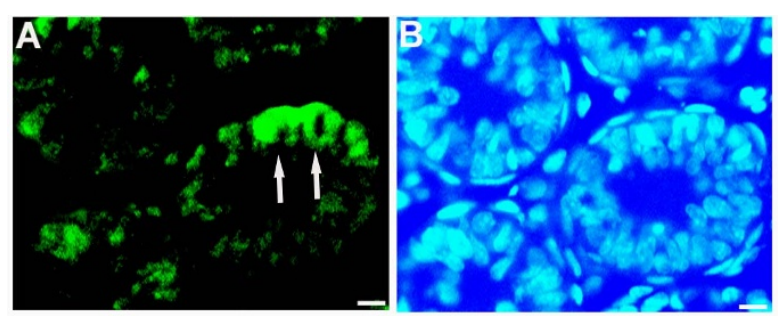

Figure 8 Subcellular localization of GON-SJTU1 in rat testis on day 7 by immunohistochemistry. GON-SJTU1 protein was detected in cytoplasm of some germ cells (green signals) (A). Corresponding DAPl image is shown in (B). Bar $=50 \mu \mathrm{m}$.

\section{Competing interests}

The authors declare that they have no competing interests.

\section{Authors' contributions}

ZY, NS, SW, and GGT carried out the experiments. ZY drafted the paper. JW initiated and mentored the study in addition to providing a valuable framework for drafting the paper. All authors read and approved the final manuscript.

\section{Acknowledgements}

This work was supported by the Kay Program and the Major Research Plan of the National Natural Science Foundation of China (No. 30630012 and No. 90919020), National Basic Research Program of China (No. 2010CB945001), Ministry of Agriculture of the People's Republic of China (No. 2009ZX08006-010B), Program of Shanghai Subject Chief Scientist (No. 10XD1402200) and the Specialized Research Fund for the Doctoral Program of Higher Education (SRFDP) in China (No. 20090073110032)

\section{Author Details}

$1 S c h o o l$ of Life Sciences and Biotechnology, Shanghai Jiao Tong University, Shanghai, 200240, China and 2School of Life Science, Nanjin Normal University, Nanjin, Jiangsu 210097, China

Received: 26 September 2009 Accepted: 12 May 2010

Published: 12 May 2010

\section{References}

1. Huckins $C$, Clermont Y: Evolution of gonocytes in the rat testis during late embryonic and early post-natal life. Arch Anat Histol Embryol 1968, 51(1):341-354

2. Novi AM, Saba P: An electron microscopic study of the development of rat testis in the first 10 postnatal days. ZZellforsch Mikrosk Anat 1968, 86(3):313-326

3. Bellve AR, Cavicchia JC, Millette CF, O'Brien DA, Bhatnagar YM, Dym M: Spermatogenic cells of the prepuberal mouse: Isolation and morphological characterization. J Cell Biol 1997, 74(1):68-85.

4. Vergouwen RP, Jacobs SG, Huiskamp R, Davids JA, de Rooij DG. Proliferative activity of gonocytes, Sertoli cells and interstitial cells during testicular development in mice. J Reprod Fertil 1991, 93(1):233-243.

5. de Rooij DG: Stem cells in the testis. Int J Exp Pathol 1998, 79(2):67-80

6. Wu J, Jester WF Jr, Laslett AL, Meinhardt A, Orth JM: Expression of a novel factor, short-type PB-cadherin, in Sertoli cells and spermatogenic stem cells of the neonatal rat testis. J Endocrinol 2003, 176(3):381-391.

7. Wu J, Jester WF Jr, Orth JM: Short-type PB-cadherin promotes survival of gonocytes and activates JAK-STAT signalling. Dev Bio/ 2005, 284(2):437-450

8. Wu J, Zhang Y, Tian GG, Zou K, Lee CM, Yu Q, Yuan Z: Short-type PBcadherin promotes self-renewal of spermatogonial stem cells via multiple signaling pathways. Cell Signal 2008, 20(6):1052-1060

9. Meng X, Lindahl M, Hyvonen ME, Parvinen M, de Rooij DG, Hess MW Raatikainen-Ahokas A, Sainio K, Rauvala H, Lakso M, Pichel JG, Westphal H, Saarma M, Sariola H: Regulation of cell fate decision of undifferentiated spermatogonia by GDNF. Science 2000, 287(5457):1489-1493.

10. Mauduit C, Hamamah S, Benahmed M: Stem cell factor/c-kit system in spermatogenesis. Hum Reprod Update 1999, 5(5):535-545.

11. Prabhu SM, Meistrich ML, Mclaughlin EA, Roman SD, Warne S, Mendis S, Itman C, Loveland KL: Expression of c-Kit receptor mRNA and protein in the developing, adult and irradiated rodent testis. Reproduction 2006, 131(3):489-499

12. Adams JM, Cory S: The Bcl-2 protein family: arbiters of cell survival. Science 1998, 281(5381):1322-1326.

13. Evan G, Littlewood T: A matter of life and cell death. Science 1998, 281(5381):1317-1322

14. Yan W, Suominen J, Samson M, Jegou B, Toppari J: Involvement of Bcl-2 family proteins in germ cell apoptosis during testicular development in the rat and pro-survival effect of stem cell factor on germ cells in vitro. Mol Cell Endocrinol 2000, 165(1-2):115-129.

15. Yan W, Suominen J, Toppari J: Stem cell factor protects germ cells from apoptosis in vitro. J Cell Sci 2000, 113(Pt 1):161-168. 
16. Yu Z, Guo R, Ge Y, Ma J, Guan J, Li S, Sun X, Xue S, Han D: Gene expression profiles in different stages of mouse spermatogenic cells during spermatogenesis. Biol Reprod 2003, 69(1):37-47.

17. Johnston DS, Wright WW, Dicandeloro P, Wilson E, Kopf GS, Jelinsky SA: Stage-specific gene expression is a fundamental characteristic of rat spermatogenic cells and Sertoli cells. Proc Natl Acad Sci USA 2008, 105(24):8315-8320.

18. Johnson KJ, Patel SR, Boekelheide K: Multiple cadherin superfamily members with unique expression profiles are produced in rat testis. Endocrinology 2000, 141(2):675-683.

19. Harrison DA, McCoon PE, Binari R, Gilman M, Perrimon N: Drosophila unpaired encodes a secreted protein that activates the JAK signaling pathway. Genes Dev 1998, 12(20):3252-3263.

20. Gilbert MM, Weaver BK, Gergen JP, Reich NC: A novel functional activator of the Drosophila JAK/STAT pathway, unpaired2, is revealed by an in vivo reporter of pathway activation. Mech Dev 2005, 122(7-8):939-948

21. Hombria JC, Brown S, Hader S, Zeidler MP: Characterisation of Upd2, a Drosophila JAK/STAT pathway ligand. Dev Bio/ 2005, 288(2):420-433.

22. Yang Z, Wu J: Mouse Dynein Axonemal Intermediate Chain 2: Cloning and Expression. DNA Cell Biol 2008, 27(9):479-488.

23. Zhang $Y, W u$ J: Molecular cloning and characterization of a new gene, Oocyte-G1. J Cell Physiol 2009, 218(1):75-83

24. Zou K, Yuan Z, Yang Z, Luo H, Sun K, Zhou L, Xiang J, Shi L, Yu Q, Zhang Y, Hou $R$, Wu J: Production of offspring from a germline stem cell line derived from neonatal ovaries. Nat Cell Biol 2009, 11(5):631-636.

25. The NCBI website [http://www.ncbi.n/m.nih.gov/blast]

26. Blom N, Gammeltoft S, Brunak S: Sequence and structure-based prediction of eukaryotic protein phosphorylation sites. J Mol Biol 1999, 294(5):1351-1362

27. Blom N, Sicheritz-Ponten T, Gupta R, Gammeltoft S, Brunak S: Prediction of post-translational glycosylation and phosphorylation of proteins from the amino acid sequence. Proteomics 2004, 4(6):1633-1649.

28. Wang W, Wine RN, Chapin RE: Rat testicular Src: normal distribution and involvement in ethylene glycol monomethyl ether-induced apoptosis. Toxicol Appl Pharmacol 2000, 163(2):125-134.

29. Jindo T, Wine RN, Li LH, Chapin RE: Protein kinase activity is central to rat germ cell apoptosis induced by methoxyacetic acid. Toxicol Pathol 2001, 29(6):607-616.

30. Lee NP, Cheng CY: Protein kinases and adherens junction dynamics in the seminiferous epithelium of the rat testis. J Cell Physiol 2005, 202(2):344-360

31. Guerra B, Siemer S, Boldyreff B, Issinger OG: Protein kinase CK2: evidence for a protein kinase CK2beta subunit fraction, devoid of the catalytic CK2alpha subunit, in mouse brain and testicles. FEBS Lett 1999, 462(3):353-357.

32. Xu X, Toselli PA, Russell LD, Seldin DC: Globozoospermia in mice lacking the casein kinase II alpha' catalytic subunit. Nat Genet 1999, 23(1):118-121.

33. Yang ZW, Wreford NG, De Kretser DM: A quantitative study of spermatogenesis in the developing rat testis. Biol Reprod 1990, 43(4):629-635.

34. Wing TY, Christensen AK: Morphometric studies on rat seminiferous tubules. Am J Anat 1982, 165(1):13-25.

35. Van Haaster LH, de Rooij DG: Spermatogenesis is accelerated in the immature Djungarian and Chinese hamster and rat. Biol Reprod 1993, 49(6):1229-1235.

36. Van Haaster LH, de Rooij DG: Cycle of the seminiferous epithelium in the Djungarian hamster (Phodopus sungorus sungorus). Biol Reprod 1993, 48(3):515-521

37. Van Haaster LH, de Rooij DG: Partial synchronization of spermatogenesis in the immature Djungarian hamster, but not in the immature Wistar rat. J Reprod Fertil 1994, 101(2):321-326.

38. Liu H, Li C, Jin L, Liu Z, Li X: Morphological studies on the development of germ cells of rat testis. Acta Anatomica Sinica 1996, 27(2):216-220.

39. Orth JM, Jester WF Jr, Qiu J: Gonocytes in testes of neonatal rats express the c-kit gene. Mol Reprod Dev 1996, 45(2):123-131.

40. Orth JM, Qiu J, Jester WF Jr, Pilder S: Expression of the c-kit gene is critical for migration of neonatal rat gonocytes in vitro. Biol Reprod 1997, 57(3):676-683.

41. Manova K, Nocka K, Besmer P, Bachvarova RF: Gonadal expression of c-kit encoded at the W locus of the mouse. Development 1990 110(4):1057-1069.
42. Sorrentino V, Giorgi M, Geremia R, Besmer P, Rossi P: Expression of the Ckit proto-oncogene in the murine male germ cells. Oncogene 1991, 6(1):149-151.

43. Dym M, Jia MC, Dirami G, Price JM, Rabin SJ, Mocchetti I, Ravindranath N: Expression of c-kit receptor and its autophosphorylation in immature rat type A spermatogonia. Biol Reprod 1995, 52(1):8-19.

doi: $10.1186 / 1477-7827-8-43$

Cite this article as: Yang et al., Molecular cloning and expression of a new gene, GON-SJTU1 in the rat testis Reproductive Biology and Endocrinology $2010,8: 43$

\section{Submit your next manuscript to BioMed Central} and take full advantage of:

- Convenient online submission

- Thorough peer review

- No space constraints or color figure charges

- Immediate publication on acceptance

- Inclusion in PubMed, CAS, Scopus and Google Scholar

- Research which is freely available for redistribution 